\title{
Paridad de género en clave republicana
}

\section{Gender parity in a republican key}

\section{Verónica María Gómez}

\author{
Universidad de Buenos Aires - Argentina
}

Revista Derechos en Acción ISSN 2525-1678/ e-ISSN 2525-1686

Año 5/Nº 15, Otoño 2020 (21 marzo a 21 junio), 554-571

DOI: https://doi.org/10.24215/25251678e413

\section{Introducción}

La sanción de la Ley 24.012 (Congreso de la Nación Argentina, 1991) que, hace casi tres décadas, estableció un cupo femenino obligatorio del treinta por ciento (30\%) para las listas a cargos electivos nacionales, fue una respuesta del Parlamento argentino a la subrepresentación grosera que entonces afectaba a las mujeres.

Antes de su aplicación, ellas apenas alcanzaban un cinco por ciento (5 \%) de la Cámara de Diputados (período 1992-1993) y un tres por ciento (3\%) del Senado de la Nación (período 2000-2001). La distancia entre esos porcentajes y la población expresaba un déficit democrático, algo insatisfactorio en los acuerdos políticos que lo admitían (Phillips, 1995).

Sin dudas, la implementación de esa norma significó un antes y un después en el acceso a la participación parlamentaria. Para el período 2018-2019, las mujeres ya ocupaban el treinta y nueve por ciento (39\%) y el cuarenta y dos por ciento ( $42 \%$ ) de las bancas de esas Cámaras, respectivamente.

Empero, cuando se estudian en detalle los términos en los que se ha dado esa inclusión y muchas de las prácticas que subsisten en el ámbito de la política, se advierte que la mayor 
presencia femenina no ha tenido correlato necesario en un complejo de relaciones más igualitarias.

Hay evidencias que son abordadas en la primera sección de este trabajo, sobre las graves dificultades que enfrentan las mujeres a la hora de intervenir en los procesos de toma de decisiones y elaboración de agendas públicas, sin que el cupo haya resultado suficiente para superarlas o siquiera ponerlas en debate.

En la segunda sección, se sostiene que las limitaciones mostradas por dicha herramienta están estrechamente vinculadas con los principios propios del liberalismo político que han nutrido la fundamentación desarrollada en defensa de las acciones afirmativas y con la palmaria separación entre la esfera pública y privada que esa doctrina filósofica ha fomentado.

Se considera que la consagración de la paridad de género dispuesta a través de la Ley 27.412 (Congreso de la Nación Argentina, 2017) en aras de acercarse a una representación legislativa de carácter proporcional, constituye una buena oportunidad para repensar ese marco teórico.

Por eso, en la última sección antes de las reflexiones finales, se propone como alternativa una argumentación de la paridad basada en las ideas republicanas del autogobierno y la libertad como no dominación, en el convencimiento de su aporte a una discusión que excede lo numérico para poner en cuestión cómo y quiénes detentan realmente el poder.

\section{La política como dominio masculino}

Como se señaló en la introducción, los parámetros androcentristas que dominan la esfera política no se han visto sustancialmente alterados con el correr de los años, a pesar del salto cuantitativo que produjo la implementación de la Ley de Cupo.

Estos patrones continúan expresándose en la marcada diferencia que persiste entre las chances de ambos géneros para ocupar lugares de decisión dentro del Parlamento. Es un claro 
ejemplo del llamado "techo de cristal" que enfrentan las mujeres que aspiran a cargos altos, una "barrera organizacional, vertical, transparente y efectiva" que las condiciona más allá de su experiencia y preparación (García Beaudoux, 2018).

A mediados de 2019, dos tercios de las autoridades del Congreso de la Nación eran varones. En el Senado ocupaban los dos cargos más importantes y en la Cámara de Diputados, todas las presidencias y vicepresidencias. Las mujeres encabezaban respectivamente, el treinta y siete por ciento (37\%) y el veintinueve por ciento (29\%) de las comisiones permanentes, cinco y diez puntos por debajo del porcentaje que obtenían en el conjunto de cada uno de esos cuerpos legislativos.

El techo de cristal expresado en esos porcentajes también obtura la participación de mujeres en espacios no alcanzados por cuotas de género, como los Ministerios del Poder Ejecutivo, el primer lugar de las listas y los cargos electivos que son unipersonales.

Para la misma etapa, en el Gobierno Nacional sobre un total de once Ministerios nueve correspondían a varones incluida la Jefatura de Gabinete. Algo similar ocurría en la Ciudad de Buenos Aires, donde las ministras eran tres entre diez y sólo el veinte por ciento (20\%) de las Comunas era presidido por jefas comunales que, en su momento, encabezaron la lista ganadora. Era paradigmática la Provincia de Buenos Aires que, aun siendo gobernada por una mujer, no contaba con una sola ministra en su gabinete y en donde nada más que cuatro de sus ciento treinta y cinco municipios eran administrados por intendentas.

Salvo casos excepcionales, las áreas de gestión asignadas a mujeres han estado identificadas con labores de cuidado e imágenes estereotipadas de lo femenino que trasladan la división sexual del trabajo reinante en la esfera privada al ámbito de lo público. Es producto de una "segregación horizontal" que las relega de otras materias como la economía, el manejo de la obra pública, la defensa y la seguridad (García Beaudoux, 2018). Si se 
repasan las jurisdicciones ministeriales y las comisiones legislativas a cargo de mujeres, aun predominan aquellas que abordan la educación, la salud, el desarrollo humano, la promoción social, la familia, la niñez, la juventud y la tercera edad.

El vaciado de los ámbitos institucionales de decisión y que muchos asuntos importantes se resuelvan al margen de mecanismos de control público (Ovejero, Martí \& Gargarella, 2004), también ha atenuado la capacidad de incidencia femenina. Son numerosas las instancias informales que reproducen la exclusión, a través de las cuales se intercambia información, se contruyen consensos y se toman resoluciones que después son ratificadas orgánicamente. Reuniones de camaradería, encuentros hasta altas horas de la noche, cenas o asados con empresarios, partidos de fútbol y otras formas de interrelación que refuerzan los vínculos y liderazgos masculinos, demarcando zonas que permanecen ajenas a las mujeres y en las que no son bienvenidas.

Del mismo modo, los criterios a partir de los cuales se pondera la personalidad o el carácter de las y los dirigentes favorecen crudamente a los varones (Phillips, 1995). Es común que se destaquen cualidades como la autoridad, la racionalidad, la firmeza, la mesura, el carisma y la oratoria que el imaginario colectivo reconoce propias de la masculinidad. Cuando las mujeres en el poder exponen esos atributos son tildadas de autoritarias, soberbias, difíciles o faltas de empatía, pero cuando adoptan otros tradicionalmente determinados como femeninos, sin medias tintas, pasan a verse maleables, indecisas o débiles. Las trayectorias políticas femeninas están siempre bajo la lupa, son más vulnerables a las críticas del público y la intimidad de las mujeres que excepcionalmente llegan a trascender, suele estar sometida a una mirada mucho más rigurosa que la que pesa sobre las vidas de sus pares varones.

Todos esos impedimentos también actúan cercenando los temas que se someten a los poderes públicos y condicionan el abordaje de muchos que son centrales para la satisfacción de 
las demandas de igualdad. Desde la sanción de la Ley de Cupo hasta ahora, hubo pequeños avances normativos, pero como regla, la incorporación de más diputadas y senadoras al Parlamento Nacional no ha garantizado respuestas efectivas frente a la realidad de vulneración de derechos y discriminación que padecen las mujeres.

Muchas veces, las mismas representantes no divisan lo anterior como un conflicto y acuerdan con situaciones que oprimen a su propio género, influidas ellas mismas por una historia y un contexto de subordinación que recorta la información a su disposición, deforma su perspectiva y moldea sus preferencias (Ovejero, Martí \& Gargarella, 2004).

El proyecto por el Aborto Legal, Seguro y Gratuito que tuvo tratamiento parlamentario en Argentina durante el 2018, grafica ese punto porque más allá del reclamo contundente del movimiento feminista y el apoyo de organismos internacionales como ONU Mujeres y la Organización Mundial de la Salud, prácticamente la mitad de las diputadas y senadoras se expresaron por la negativa a través de un voto en contra o una abstención.

Esa divergencia es especialmente problemática porque estrecha las expectativas sociales en torno a la importancia al sexo de quienes nos representan, en la medida en que el proceder de ambos géneros en los espacios de representación no varía significativamente y una asamblea legislativa balanceada no asegura que se atiendan en forma adecuada las necesidades e intereses de las mujeres (Phillips, 1995).

Ante ese escenario en el que se ponen de manifiesto múltiples desigualdades, la pregunta que se impone es por qué la vigencia de la Ley de Cupo no bastó para desentrañarlas ni coadyuvó al desarrollo de estrategias dirigidas a quebrar la impronta eminentemente masculina que impera en la arena política.

En la próxima sección, se ensaya una respuesta que entrelaza esa contrariedad con los fundamentos liberales que han sustentado teóricamente este tipo de medidas de acción positiva. 


\section{Los inconvenientes de la fundamentación liberal}

Con raíces en la filosofía contractualista, el liberalismo establece una separación drástica, una dicotomía entre la esfera de lo público y lo privado. La primera asociada a lo universal, racional e imparcial, se encuentra regida por el contrato social, la convención entre individuos preexistentes, libres e iguales entre sí. Como contrapartida, la segunda todavía sujeta a las leyes de la naturaleza, tiene como centro a la familia y se relaciona con lo particular y emocional.

Comúnmente no se advierte que esa distinción entre la política y la vida doméstica propone, al mismo tiempo, una división sexual. Según John Locke (1821 [1690]), las diferencias naturales convierten a las mujeres en el "sexo más débil" y avalan la sumisión de la esposa al marido cuya voluntad debe primar en todas las decisiones, por ser el más fuerte, hábil y capaz. Como subordinadas naturales, las mujeres son excluidas de la condición de individuos y la participación en el mundo público (Pateman, 2018).

El ámbito privado se presenta como un marco para que los individuos ejerzan su juicio y persigan sus intereses, protegidos de cualquier interferencia estatal. Las leyes en sí mismas, son vistas como una intromisión a la libertad personal. La política debe permanecer abstraída de esa esfera, ubicándose por encima de los intereses en conflicto y las relaciones desigualitarias que se registran en su seno.

La democracia se vuelve indiferente a los procesos a partir de los cuáles se configuran las preferencias, aunque se vean falseadas por un transfondo de distribución inequitativa del poder y el funcionamiento de instituciones sociales discriminatorias (Sunstein, 2004).

Bajo ese esquema teórico, las acciones afirmativas entendidas como aquellas que establecen prioridades o cupos a favor de las y los miembros de determinados grupos sociales con el fin de corregir desigualdades de hecho, no tienen cabida porque consisten en una intromisión no deseada del Estado que desconoce 
el mérito evaluado en base a la competencia y la experiencia de las personas, como postulado básico a partir del cual deben asignarse los cargos públicos. El cupo de género es inadmisible porque ignora la supuesta incapacidad de las mujeres para desenvolverse en la esfera política y desarrollar un sentido de justicia que es, en esencia, una virtud pública, convencional. La presencia de mujeres dentro de los poderes estatales es percibida como una amenaza, un desorden que se resuelve segregándolas a las tareas de reproducción (Pateman, 2018).

Recién con la irrupción del liberalismo igualitario de John Rawls se genera dentro de esta corriente de pensamiento, un campo fértil para la justificación de las acciones afirmativas. Aunque el autor nunca escribió en lo personal sobre esas medidas, sí se expresó a favor de la importancia de defender su constitucionalidad e influyó en su debate a partir del clima intelectual que produjo (Nagel, 2003).

En su Teoría de la Justicia, Rawls (2006 [1971]) disputa expresamente al mérito, no tanto como requisito para el acceso a determinados puestos, sino como razón exclusiva del éxito individual y las disparidades existentes en el seno de una sociedad. Allí, reconoce que "los hombres nacidos en posiciones sociales diferentes tienen diferentes expectativas de vida" y a modo de respuesta enuncia el principio de la diferencia que consagra la igualdad de oportunidades y brinda sostén a la disposición de desigualdades económicas y sociales siempre que resulten en beneficio de los menos aventajados.

Sin embargo, los argumentos a favor de las acciones afirmativas que se elaboraron sobre esa base fracasaron en el objetivo de lograr que los efectos de las cuotas - en particular, de género - fueran más allá de asegurar umbrales mínimos de presencia a los grupos excluidos.

Entre ellos, pueden mencionarse los que conciben a las acciones afirmativas como una política que pretende reparar las consecuencias de un pasado injusto y ayuda a contrarrestar la discriminación encubierta o inconsciente que continúa ejerciéndose 
contra distintas minorías. Su finalidad es lidiar con una falla en la igualdad de oportunidades vinculada a las desventajas que enfrentan las personas pertenecientes a sectores con una historia de opresión, en la competencia por el ingreso a determinadas instituciones (Nagel, 2003).

Por otro lado, aparecen las justificaciones que defienden la denominada "discriminación inversa" a pesar de la pérdida que conlleva para algunos individuos, al amparo de los beneficios que comporta para la comunidad en general, tanto en un sentido utilitarista como idealista (Dworkin, 1989).

La diversidad de quienes tienen a su cargo roles políticos, empresariales o profesionales importantes es apreciada cual valor transcendente (Dworkin, 2000), que de alcanzarse puede aminorar las tensiones sociales y construir una sociedad más equitativa (Dworkin, 1989)

Esas razones que, en una etapa inicial, se esbozaron como cimiento de las acciones afirmativas que utilizaban clasificaciones raciales, son las que también han predominado para apoyar teóricamente a las cuotas de género, como se observa en buena parte de los discursos expresados en las sesiones del Congreso de la Nación, en las que se aprobó la aludida Ley $24.012^{1}$.

El primer inconveniente de estas elucidaciones es que entienden a las acciones afirmativas como una especie de mal necesario. Consideran que las versiones más fuertes de este tipo de medidas son "intrínsecamente indeseables", más allá de su eventual legitimidad como método para perseguir determinados objetivos concernientes al bienestar de la Nación (Nagel, 1981).

En ese sentido, resaltan su excepcionalidad y ponen de manifiesto una preocupación constante por acotar al máximo

\footnotetext{
Para profundizar véase Diario de Sesiones de la Cámara de Diputados, 46 Reunión, Sesión Ordinaria de Prórroga (Especial) del 6/7 de noviembre de 1991. Con los alcances que se analizan a continuación, estos argumentos están presentes de manera desordenada, entre otros, en los discursos de Botella (p. 4094), Álvarez (p. 4110), Quarrachino (p. 4.123), Lázara (p. 4127), Estevez Boero (p. 4.129), Berhongaray (p. 4.137), Raimundi (p. 4.149), Ortiz Pellegrini (p. 2156) y Gómez Miranda (p. 4.169).
} 
sus alcances, ansiando encorsetar la aplicación de las acciones afirmativas a ciertos ámbitos - en especial, la educación superior - donde se espera, contribuyan a mejorar las oportunidades de sus destinatarios, en las selecciones que "de la manera normal" otros ciudadanos realicen de empleados, profesionales o funcionarios públicos (Dworkin, 2000-B).

Estas medidas son imaginadas como mecanismos establecidos para reducir una injusticia social pasada, presente o futura, sin que esto implique asegurar una representación proporcional de los distintos grupos (Nagel, 1981), ni que las instituciones deban tener la misma composición que la sociedad como un todo (Dworkin, 2000-B). Esos reparos, hacen que sea muy dificil extender su potencial argumentativo a la paridad de género.

Tales visiones enfatizan el carácter temporal de las acciones afirmativas aunque, curiosamente, ninguna se detiene a analizar las causas de las desigualdades existentes ni se plantea como meta revertirlas. Sólo ponen la lupa en algunos de los efectos negativos que producen en los grupos afectados o la armonía de la vida colectiva, en procura de morigerarlos.

Entonces, tampoco sorprende que centren sus observaciones en las preferencias de los sectores dominantes para desalentar prejuicios (Dworkin, 1989) y pasen por alto las formas en que los contextos opresivos condicionan las opciones de los propios sectores desventajados, en ocasiones, al extremo de favorecer actitudes y prácticas de sus integrantes, funcionales a la reproducción de la discriminación.

Al margen de lo expuesto, todo indica que la principal limitación que afronta el liberalismo igualitario para indagar acerca de los magros resultados de la aplicación de cupos de género, tiene que ver con que ni Rawls ni los filósofos que dialogan con él en pos de una democracia progresista, problematizan la tensión entre convención y naturaleza en la que se sostiene la separación de la esfera pública y la vida doméstica para asignar roles diferentes a varones y mujeres (Pateman, 2018). 
En su obra, Rawls (2006 [1971]) supone que las personas participantes en la posición original son "cabezas de familia" y reivindica a la familia monógama como una gran institución social que está basada en lazos afectivos. Al hacerlo, no sólo evidencia el arraigo que tienen las creencias patriarcales sobre las características adecuadas del individuo (Pateman, 2018), sino que también deja fuera del alcance de los principios de justicia a las relaciones de dominación que se dan en el ámbito doméstico que sigue siendo el adecuado para la mujer. La famila interactúa con la esfera pública a través del padre que representa los intereses de sus miembros como si fueran comunes y negando cualquier conflicto interno.

No es extraño que la irrupción de las mujeres en la escena pública sea percibida como un hecho anómalo o como una ampliación de las labores de cuidado que desempeñan en sus hogares (Pateman, 2018) y que se traduce en la división también sexual de las responsabilidades políticas, descripta en la segunda sección de este trabajo. Esto se concatena con los discursos que - incluso desde posturas feministas - reinvidican diferencias morales entre los géneros y destacan como virtud particular de las mujeres a la sensibilidad social.

En distintas interpretaciones republicanas, las asimetrías en el poder interpersonal son en sí mismas objetables y asoman como un enemigo real de la libertad (Pettit, 2012), ofreciendo junto a la noción de autogobierno, un buen punto de partida para revisar las propuestas liberales y animarse a darle forma - como en la próxima sección - a nuevas argumentaciones de la paridad de género.

\section{Una perspectiva republicana de la paridad de género}

Las elecciones nacionales de Argentina celebradas en octubre de 2019 fueron las primeras donde, en cumplimiento de la mencionada Ley 27.412, las listas para ingresar a la Cámara de Diputados tuvieron que intercalar varones y mujeres con 
la aspiración de llegar en el mediano plazo, a una integración paritaria de ese cuerpo legislativo ${ }^{2}$.

Ya no se trata de instaurar un piso mínimo de representación femenina sino de promover que la proporción de mujeres en la sociedad se vea reflejada en la distribución de las bancas del Congreso Nacional. Es un cambio no menor que abre la oportunidad de desplegar un nuevo horizonte teórico, superador de la concepción restrictiva y excepcional de la discriminación positiva o inversa con la que el liberalismo igualitario ha convalidado las acciones afirmativas.

La premisa republicana del autogobierno puede ser útil para fundar que quienes conforman la mitad postergada de la población tengan acceso a las listas de cargos electivos en condiciones de igualdad, pero también y fundamentalmente, para interrogarse acerca de cómo conseguir que esa paridad de género se traduzca en la remoción de los muchos obstáculos que en pleno Siglo XXI, impiden el balance de poder entre varones y mujeres. El enfoque que vincula la "presencia" de las mujeres en los órganos de gobierno con la representación y la participación política, es una invitación a este tipo de razonamiento (Phillips, 1995).

Aproximándonos a una caracterización del autogobierno, Philip Pettit (2012) relaciona la legitimidad política con un sistema de control democrático en el que las chances de participar están disponibles por igual para cada ciudadano y ciudadana. Conforme su formulación, esto demanda que las personas tengan la misma capacidad de ejercer influencia sobre el gobierno y compartan equitativamente la posibilidad de fijar a través de esa influencia, la dirección en la que actúa el Estado, para que resulte aceptable por el conjunto.

\footnotetext{
2 En el mismo sentido, la Presidencia de la Cámara de Diputados de la Nación Argentina dictó la Resolución N ${ }^{0} 1657$ del 13 de diciembre de 2019, a efectos de extender los alcances de la Ley 27.412 y garantizar la paridad de género en la designación de las presidencias de las comisiones de ese cuerpo legislativo.
} 
Delineado en esos términos, el autogobierno implica más que vehiculizar el ingreso de mujeres a una asamblea legislativa y nos interroga acerca de si los roles que ellas asumen dentro de ese y otros poderes del Estado, son los adecuados para que su influencia sea determinante. En particular, favorece una visibilización crítica de los techos de cristal y la segregación horizontal que -descriptos en la primera sección- hacen que las opiniones de las dirigentes políticas no tengan peso en los niveles más altos del poder o sean menospreciadas en la resolución de un sinnúmero de problemas trascendentes para la sociedad.

La preocupación que expresan las y los republicanos por trazar un diseño institucional que promueva una deliberación pública y transparente de los asuntos que conciernen al bien común, también desalienta el funcionamiento de cualquier espacio informal de decisión que tenga como consecuencia la exclusión de las mujeres. El proceso deliberativo es alterado por las disparidades de poder que permiten que un sector condicione la participación de otro.

Es que, como indica Pettit (2012), la capacidad de influir en el gobierno exige que las personas disfruten de una esfera de decisiones con relativa indepedencia de los demás y de ese modo se emparenta con otro pilar del pensamiento republicano: la libertad como no dominación, que es vulnerada cuando la voluntad de una persona está subordinada al poder de interferencia de un tercero, aunque nunca se concrete.

Así como la legitimidad política requiere que la libertad entendida bajo esa óptica sea respetada por parte del Estado, para este autor la justicia social reclama que también esté presente en las relaciones entre individuos, entre grupos, o entre individuos y grupos. Pettit (2012) insinúa que es dificil que una persona sojuzgada en el ámbito privado pueda tener injerencia en los quehaceres estatales. Esa faceta de su desarrollo teórico puede hacer una gran contribución al debate sobre las acotadas repercusiones cualitativas que han tenido las cuotas de género, en tanto anima a desarticular una organización social que 
perpetúa mecanismos estructurales de dominación y revalida patrones de comportamiento que importan una invasión en la facultad de elegir de las mujeres.

Admitir que el contexto recorta y/o manipula las opciones de las que ellas disponen, es un paso imprescindible para reflexionar desde otro ángulo, acerca de la actitud complaciente que muchas militantes y dirigentes políticas muestran hacia el papel secundario y hasta decorativo que se les reserva. También para fomentar el desarrollo y fortalecimiento de una autoconciencia femenina en torno a que - en la definición de prioridades de agenda y en el tratamiento de variadas cuestiones económicas, laborales, sanitarias y culturales - los intereses de las mujeres son distintos y pueden estar en conflicto con los de los varones.

Cass Sunstein (1991) examina todavía más acabadamente el carácter endógeno de las preferencias personales que, lejos de ser fijas o estables, se adaptan a un amplio rango de factores entre los que enumera a la existencia de "condiciones de fondo injustas". En ese marco, describe cómo la maniobra de culpar a las víctimas de la discriminación opera para deteriorar su autoestima, nublar su discernimiento y hacer que asuman como natural e inevitable la situación de injusticia que soportan.

Para este filósofo, corregir los procesos a través de los cuáles se forman las preferencias es un objetivo de la democracia y la valoración positiva que hace de las propuestas de representación proporcional (Sunstein,1991), bien es susceptible de extenderse a las políticas de paridad de género, en cuanto debieran facilitar el escrutinio de las preferencias y el reconocimiento de las funciones creativas del desacuerdo, aumentando la probabilidad que los resultados políticos incorporen todos los puntos de vista y sean una expresión saludable de valores colectivos. Sería coherente con su interpretación respecto a que el principio constitucional de igualdad veda las "castas" o las "ciudadanías de segunda clase" y prohíbe convertir a características moralmente irrelevantes y altamente visibles como el sexo de las personas, en una base de desventaja sistémica (Sunstein, 1998). 
En consonancia con lo anterior, tanto Pettit como Sunstein consienten la legitimidad de las intervenciones estatales dirigidas a corregir las asimetrías de poder que tienen lugar en el ámbito doméstico. En aras de la justicia social, el primero expone la necesidad de brindar recursos y protección para garantizar la libertad como no dominación en las relaciones particulares y ofrece como herramienta la sanción de leyes que empoderen a la parte vulnerada (Pettit, 2012). El segundo, aprueba las interferencias del gobierno que procuran resolver las complicaciones relativas al origen de las preferencias que las personas expresan y los esfuerzos por avanzar en la igualación de la distribución de las labores de cuidado (Sunstein, 1991).

Estas ideas republicanas desdibujan la distinción entre la esfera de lo público y lo privado, además de atacar la división sexual de roles que el liberalismo -incluso igualitario- ha desprendido de esa separación. De esa forma, sirven al impulso de un cambio sustancial de la percepción social que atribuye cualidades diferenciadas a cada género y jerarquiza aquellas consideradas masculinas. Dejan de condenar el entrometimiento de las mujeres en ciertas áreas de gobierno y convocan a utilizar la misma vara para medir el desempeño de los y las dirigentes políticos.

La teoría de la justicia social de Pettit y los análisis que Sunstein hace de las preferencias personales bosquejan una buena respuesta a las advertencias que Anne Phillips (2004) hace en relación a una eventual conexión entre el feminismo y las tesis republicanas, a los que califica de "aliados dificiles" en virtud de la dicotomía demasiado tajante entre lo público y privado que -según ella- todavía abrazan estas últimas y el valor que le asignan al intereses general y a la imparcialidad en desmedro del autointerés, colocando una carga pesada sobre los grupos que recién comienzan a articular sus reclamos distintivos.

Esto no quiere decir que las dudas de la autora no sean legítimas, incluso si se toman como referencia a estos dos filósofos. Si bien intuye que en la práctica es casi imposible que 
existan escindidas, Pettit (2012) ubica a la legitimidad política en un lugar de predominio sobre la justicia social porque -conforme su criterio- una falla en el primer terreno compromete más profundamente la robustez de la libertad mientras que una ocurrida en el segundo sólo hace vulnerable a las personas ante algunos de sus conciudadanos. La posición de Sunstein también se vuelve errática porque cuando subraya que el contenido de las acciones afirmativas es una responsabilidad democrática y tiene que ser sometido a la deliberación pública (Sunstein, 1996), le resta importancia a su propio llamado de atención respecto a cómo ese proceso se ve distorsionado por el hecho que existan grupos más organizados que otros producto de disparidades en el bienestar y la influencia de la que gozan, y distintas clases de coerción pública y privada (Sunstein, 1991).

Más allá de esas disgresiones, ambos introducen elementos que interesan al objetivo de revelar la contradicción práctica que existe entre la igualdad política fomal y la subordinación social de las mujeres. Aceptar que la vida política y la personal están indisolublemente conectadas, sin prioridades ni jerarquías, es una condición indispensable para que la paridad de género en las listas de cargos electivos tenga correlato en un ejercicio más igualitario del poder.

No vamos a lograr una ciudadanía democrática plena de las mujeres hasta tanto se generen cambios radicales en la esfera doméstica que involucren a los varones y liberen a las mujeres de la función exclusivamente reproductiva que guardó para ellas el contractualismo (Pateman, 2018).

\section{Reflexiones finales}

Como en otras partes del mundo, la aplicación del cupo femenino en Argentina vino a resaltar la importancia democrática de la representación femenina y trajo aparejado un incremento relevante en el número de las bancas ocupadas por mujeres en el Congreso Nacional. El valor de esa conquista es enorme pero no quita que transcurridas más de tres décadas 
desde su aprobación, en los hechos, las elites políticas continúan siendo predominantemente masculinas.

Los datos empíricos que se describen en forma sintética en la primera sección, dan cuenta de la preponderancia que aun conservan los varones en el acceso a puestos no alcanzados por esa $\mathrm{u}$ otra acción afirmativa, otros que tienen altos niveles de exposición y capacidad de decisión, o se refieren a temáticas que exceden lo específicamente social. También revelan cómo la matriz masculina de los mecanismos de poder, retroalimentados por un contexto social que tergiversa los intereses que las mujeres expresan, sesga la deliberación y circunscribe las agendas públicas.

En estas páginas, se ha intentado relacionar la minúscula eficacia del cupo femenino como disparador de medidas capaces de revertir esas y otras desigualdades de género en la política, con los fundamentos liberales que han primado como soporte jurídicopolítico de las acciones afirmativas reduciéndolas a dispositivos excepcionales de discriminación inversa o positiva, con alcance temporal y restringido en su contenido, destinados a ajustar alguna incorrección en la igualdad de oportunidades y achicar el impacto de las injusticias sociales, sin combatir sus causas y favoreciendo un status quo que pospone a las mujeres. No es casual que la división sexual entre lo público y lo privado heredada del contractualismo clásico, no sea cuestionada sustancialmente y se mantenga fuera de la órbita de la discusión democrática.

La paridad de género en las listas ha inaugurado otro capítulo en la lucha por la igualdad política que al encaminarse a una composición legislativa de varones y mujeres que espeje a la sociedad, ya no admite ser comprendido bajo el cariz de las acciones afirmativas y obliga a ensayar nuevas líneas argumentales, más ambiciosas en su finalidad transformadora.

De acuerdo a lo esgrimido en la sección anterior, los pilares republicanos del autogobierno y la libertad como no dominación constituyen un insumo valioso para esa tarea porque nos interpelan acerca de la capacidad de influencia de las representantes femeninas en los procesos formales e informales de 
toma de decisiones y los efectos que en su carrera y su práctica política, tienen las discriminaciones de género que se suceden en el ámbito privado.

El acceso a los cargos electivos es un pre-requisito indispensable aunque insuficiente si la meta perseguida es que las mujeres tengan el mismo poder de incidir en la cosa pública que los varones. Para alcanzarla hace falta deconstruir la relación antagónica entre lo personal y lo político, en busca de un reparto equitativo de las responsabilidades familiares y una participación pública verdaderamente igualitaria.

No se sugiere que la filosofía republicana encaje a la perfección con las inquietudes del movimiento feminista. No obstante, su notoria incomodidad con que áreas importantes de decisión individual estén sujetas a la voluntad de otras personas, la sitúa mejor que al liberalismo de cara al desafío inclusivo de propugnar una distribución más igual del poder.

Es legítimo preguntarse si esa lógica que parece funcionar como sustentación de la paridad de género con miras a acentuar su dimensión cualitativa, puede extenderse a la incorporación proporcional de otros grupos excluidos de las instancias de representación, sin riesgos de agudizar la fragmentación social. Pero esa es materia de otro trabajo.

\section{Referencias}

Congreso de la Nación Argentina (6 de noviembre de 1991). Ley de Cиро Femenino. Boletín Oficial del 3 de diciembre de 1991. Recuperada de http://servicios.infoleg.gob.ar/infolegInternet/ anexos/0-4999/411/norma.htm.

Congreso de la Nación Argentina (22 de noviembre de 2017). Ley de Paridad de Género. Boletín Oficial del 15 de diciembre de 2017. Recuperada de http://servicios.infoleg.gob.ar/infolegInternet/anexos/300000-304999/304794/norma.htm.

Dworkin, R. (1989). Los derechos en serio. Barcelona: Ariel.

Dworkin, R. (2000). Affirmative Action: Does it work? Sovereign Virtue: The Theory and Practice of Equality, 386-408. 
Dworkin, R. (2000-B). Affirmativa Action: Is it Fair? Sovereign Virtue: The Theory and Practice of Equality, 409-426.

García Beaudoux, V. (2018). Carreras de Obstáculos y Laberintos de Cristal. El Atlas de la Revolución de las Mujeres. Le monde diplomatique, 66-69.

Locke, J. (1821 [1690]). Two Treatises of Government. Londres: Whitmore and Fenn y otros. Recuperado de https://archive. org/ details/twotreatisesofg00lockuoft.

Nagel, T. (1981). A defense of affirmative action. Report from the Center for Philosophy \& Public Policy, 6-9.

Nagel, T. (2003). John Rawls and Affirmative Action. The Journal of Blacks in Higher Education, 82-84.

Ovejero, F., Martí, J. L. \& Gargarella, R. (2004). Introducción. La alternativa republicana. En F. Ovejero, J. L. Martí \& R. Gargarella, Nuevas ideas republicanas. Autogobierno y libertad (pp. 11-73). Barcelona: Paidós.

Pateman, C. (2018). El desorden de las mujeres. Democracia, feminismo y teoría política. Buenos Aires: Prometeo Libros.

Pettit, P. (2012). On the people's terms. Cambridge: Cambridge University Press.

Phillips, A. (1995). The Politics of Presence. Oxford: Clarendon Press.

Phillips, A. (2004). Feminismo y Republicanismo: ¿Es ésta una alianza plausible? En F. Ovejero, J. L. Martí, \& R. Gargarella, Nuevas Ideas Republicanas. Autogobierno y Libertad (pp. 263283). Barcelona: Paidós.

Rawls, J. (2006 [1971]). Teoría de la Justicia. Cambridge: The Belknap Press of Harvard University Press.

Sunstein, C. R. (1991). Preferences and Politics. Philosophy \& Public Affairs. Volúmen 20. No 1, 3-34.

Sunstein, C. R. (1996). Public Deliberation, Affirmative Action, and the Supreme Court. California Law Review, 1179-1999.

Sunstein, C. R. (1998). Affirmative Action, Caste and Cultural Comparisons Correspondence. Michigan Law Review, 1311-1320.

Sunstein, C. R. (2004). Más allá del resurgimiento republicano. En F. Ovejero, J. L. Martí \& R. Gargarella, Nuevas Ideas Repúblicanas. Autogobierno y Libertad (pp. 137-190). Barcelona: Paidós. 